\title{
Sol-gel pyrolysis and photoluminescent characteristics of europium-ion doped yttrium aluminum garnet nanophosphors
}

\author{
Chung-Hsin Lu*, Wei-Tse Hsu, J. Dhanaraj ${ }^{1}$, R. Jagannathan ${ }^{1}$ \\ Electronic and Electro-Optical Ceramics Laboratory, Department of Chemical Engineering, National Taiwan University, Taipei, Taiwan, ROC
}

Received 16 March 2003; received in revised form 5 December 2003; accepted 13 December 2003

Available online 21 April 2004

\begin{abstract}
Europium-ion doped $\mathrm{Y}_{3} \mathrm{Al}_{5} \mathrm{O}_{12}$ garnet nanophosphors (YAG:Eu ${ }^{3+}$ ) with wide ranging size tunability $(40-150 \mathrm{~nm})$ have been prepared via a sol-gel pyrolysis method employing a fuel system that combined urea and polyvinyl alcohol (PVA). Well dispersed nanoparticles were prepared at $1000^{\circ} \mathrm{C}$. This temperature is lower than that required for synthesizing YAG:Eu ${ }^{3+}$ via the solid-state reaction route. The particle size and morphology of the synthesized powders are found to have critical dependence on the oxidizer (metallic nitrates) to fuel ratio. The importance of using an organic polymeric dispersion matrix to obtain well dispersed YAG:Eu ${ }^{3+}$ nanoparticles has been demonstrated. The photoluminescene properties of the prepared YAG:Eu ${ }^{3+}$ phosphors are profoundly dependent on the preparation conditions. The emission intensity of well dispersed YAG:Eu ${ }^{3+}$ nanoparticles is found to be much stronger than that of the bulk sample. The excitation spectrum of well dispersed nanoparticles shows an extension of the excitation peak in the high-energy region. These unique properties of YAG:Eu ${ }^{3+}$ nanoparticles can be rationalized by considering numerous surface states due to the large surface area to volume ratio of the nanoparticles. In addition, using the hypersensitive ${ }^{5} \mathrm{D}_{0} \rightarrow{ }^{7} \mathrm{~F}_{2}$ transition of $\mathrm{Eu}^{3+}$ as a local probe, the role of surface states that modify the optical properties of YAG: $\mathrm{Eu}^{3+}$ nanophosphors has also been illustrated.
\end{abstract}

(C) 2004 Elsevier Ltd. All rights reserved.

Keywords: Sol-gel process; $\mathrm{Y}_{3} \mathrm{Al}_{5} \mathrm{O}_{12}$; Nanoparticles; Phosphors

\section{Introduction}

Yttrium aluminum garnet $\mathrm{Y}_{3} \mathrm{Al}_{5} \mathrm{O}_{12}$ (YAG) has wide applications from conventional structural ceramics to photonics. ${ }^{1,2}$ YAG doped with lanthanides such as $\mathrm{Nd}^{3+}$ and $\mathrm{Ce}^{3+}$ is already used in the construction of dye lasers and new generation lighting devices. ${ }^{3,4} \mathrm{Eu}^{3+}$ doped YAG phosphors and thin films also have the potential for application in field emission devices. ${ }^{5,6}$ Phosphors for field emission and vacuum fluorescent display devices have critical dependence on their particle sizes. Optimum performance in these devices can be achieved by employing ultrafine phosphor particles. ${ }^{7,8}$

In view of the tremendous scope for application, a number of physicochemical methods have been employed for the

\footnotetext{
* Corresponding author. Tel.: +886-2-2363-5230; fax: +886-2-2362-3040.

E-mail address: chlu@ccms.ntu.edu.tw (C.-H. Lu).

${ }^{1}$ Present address: Luminescence Group, CECRI (CSIR), Karaikudi-630006, Tamil Nadu, India.
}

preparation of YAG powders. In the typical solid-state synthesis method, $\mathrm{Y}_{2} \mathrm{O}_{3}$ and $\mathrm{Al}_{2} \mathrm{O}_{3}$, used as the starting materials, are mixed and heated at high temperature $\left(\sim 1600^{\circ} \mathrm{C}\right)$ for several hours. Two intermediate phases, $\mathrm{YAM}\left(\mathrm{Y}_{4} \mathrm{Al}_{2} \mathrm{O}_{9}\right.$, yttrium aluminium monoclinic) and $\mathrm{YAP}\left(\mathrm{YAlO}_{3}\right.$, yttrium aluminium perovskite) are easily formed as by-products with YAG, even if the synthesis is performed with stoichiometric mixtures of $\mathrm{Y}_{2} \mathrm{O}_{3}$ and $\mathrm{Al}_{2} \mathrm{O}_{3} .{ }^{9}$ For the formation of the pure YAG phase, repeated calcination processes and prolonged heating are required. ${ }^{10}$ The prolonged heating at elevated temperatures results in inevitable coarsening of the grains. Therefore, the formed particles tend to exhibit a large grain size, a wide size distribution, and irregular morphology.

For correcting these drawbacks of the solid-state reaction process, different kinds of wet-chemical processes have been applied to synthesize YAG phosphors. In these chemical routes, precise control of particle size and chemical homogeneity is possible since the chemical reaction in the liquid phase takes place at the molecular level. Among various chemical routes such as co-precipitation, ${ }^{11,12}$ spray drying, ${ }^{13,14}$ and sol-gel pyrolysis, ${ }^{15-17}$ the last one has an 
edge over the other chemical routes. It has the advantages of both wet-chemical and solid-state synthesis methods, such as low temperature synthesis $\left(1000^{\circ} \mathrm{C}\right)$, well dispersed nanoparticles, inexpensive precursors, ease of preparation, and large upscalability. Thus, these foregoing facts justify the sol-gel polymer pyrolysis employing urea and polyvinyl alcohol (PVA) combined fuel system as a more facile method for the preparation of YAG powders.

In the sol-gel polymer pyrolysis process, the preparation of inorganic powder is based on pyrolyzing the mixtures of the corresponding metallic nitrates acting as reactants and a polymeric gel base acting as dispersion medium in the presence of suitable fuels by a self-sustained combustion process. The effective total valency ratio, $\Phi$, between the oxidizer (metallic nitrates) and fuels (urea and PVA) is critical in determining the sustainability of the combustion reaction and, hence, the acquirement of the desired monophasic products. ${ }^{15}$ The effective total valency ratio $(\Phi)$ is defined as 8,15

$\Phi=-\frac{\sum x_{i} M_{i} n_{i}}{\sum x_{j} F_{j} n_{j}}$

where $M_{i}$ and $F_{j}$ are the number of ions present in oxidizers and fuels, respectively, $x_{i}$ and $x_{j}$ are the corresponding number of units in oxidizers and fuels, respectively, and $n$ is the corresponding valence for each species. This ratio is critical for the growth of the ceramic particles prepared using the sol-gel polymer pyrolysis method. However, the information regarding the growth of phosphors prepared with $\Phi$ values different from unity is limited. In the present investigation, an attempt has been made to understand the growth and luminance of YAG: $\mathrm{Eu}^{3+}$ phosphors prepared with different values of $\Phi$. Two different fuel systems (PVA and urea combined system, and urea only system) were applied to prepare YAG: $\mathrm{Eu}^{3+}$ phosphors to elucidate the effects of fuel systems on the growth as well as the luminance characteristics. The influence of the particle sizes on the photoluminescene properties of the prepared YAG:Eu ${ }^{3+}$ phosphors was also examined.

\section{Experimental}

The sol-gel pyrolysis method employed in this investigation for the preparation of YAG:Eu ${ }^{3+}$ nanophosphors is described in Fig. 1. In all the above preparations, the $\mathrm{Eu}^{3+}$ concentration was fixed at an optimum value of $5 \mathrm{~mol} \%$ with respect to $\mathrm{Y}^{3+}\left(\mathrm{Y}_{2.85} \mathrm{Eu}_{0.15} \mathrm{Al}_{5} \mathrm{O}_{12}\right)$. Samples were prepared by combining PVA (with degree of polymerization around 1500 ) with urea together as fuel. Two sets of samples were prepared with different fuel systems, where $\mathrm{A}\left(\mathrm{A}_{1}, \mathrm{~A}_{2}\right.$, and $A_{3}$ ) denotes the mixture of equi-molar PVA and urea used as fuel; $B\left(B_{1}, B_{2}\right.$, and $\left.B_{3}\right)$ represents the system using only urea as the fuel, and the subscripts $(1,2$, and 3$)$ indicate different oxidizer to fuel ratios ( $\Phi$, equal to $0.5,1$, and 2.0 , respectively). The fuel system of each sample is summa-

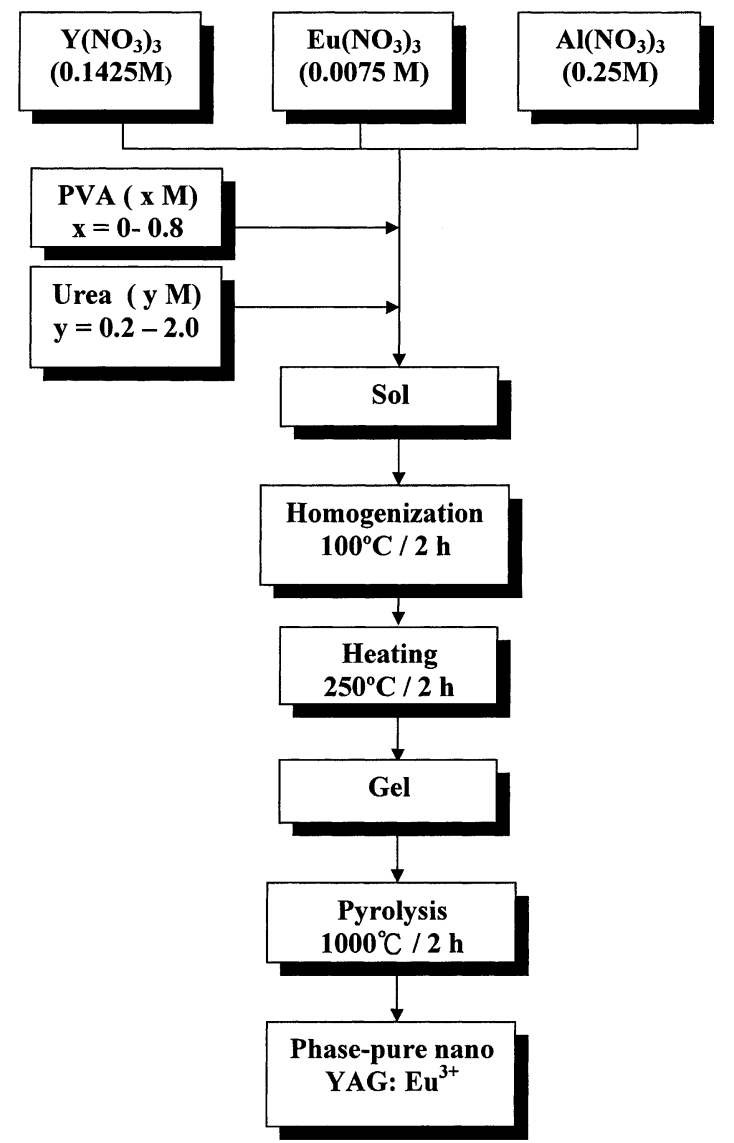

Fig. 1. Flow chart showing various stages in the preparation of YAG:Eu ${ }^{3+}$ phosphors via sol-gel polymer pyrolysis.

rized in Table 1. The corresponding nitrates of each element were dissolved in deionized water, followed by adding the designed amount of PVA and urea solution. The resulting solution was stirred and heated at $150^{\circ} \mathrm{C}$ on a hot plate for $2 \mathrm{~h}$. The clear solution was turned into yellowish gel by heat treatment at $250^{\circ} \mathrm{C}$ for $2 \mathrm{~h}$. The dry gel was then calcined at $1000^{\circ} \mathrm{C}$ for $2 \mathrm{~h}$, and uniform white powder was obtained. On the other hand, YAG: $\mathrm{Eu}^{3+}$ powders were also prepared via the solid-state reaction process using $\mathrm{Al}_{2} \mathrm{O}_{3}, \mathrm{Y}_{2} \mathrm{O}_{3}$, and

Table 1

Preparation conditions and characteristics of $\mathrm{YAG}: \mathrm{Eu}^{3+}$ phosphors using sol-gel pyrolysis

\begin{tabular}{lllrll}
\hline Fuel system & Sample & $\Phi^{\mathrm{a}}$ & $T_{\mathrm{f}}(\mathrm{K})^{\mathrm{b}}$ & $C(\%)^{\mathrm{c}}$ & $\begin{array}{l}\text { Crystallite } \\
\text { size }(\mathrm{nm})\end{array}$ \\
\hline PVA and urea & $\mathrm{A}_{1}$ & 0.5 & 2204 & 35.8 & 41.1 \\
& $\mathrm{~A}_{2}$ & 1.0 & 2146 & 67.9 & 45.2 \\
& $\mathrm{~A}_{3}$ & 2.0 & 700 & 59.3 & 43.1 \\
Urea & $\mathrm{B}_{1}$ & 0.5 & 2036 & 10.6 & 25.8 \\
& $\mathrm{~B}_{2}$ & 1.0 & 1607 & 23 & 43.1 \\
& $\mathrm{~B}_{3}$ & 2.0 & 390 & 17.7 & 36.2 \\
\hline
\end{tabular}

${ }^{\text {a }} \Phi$ : the ratio between the sum of oxidizing valencies and the sum of reducing valencies.

${ }^{\mathrm{b}} T_{\mathrm{f}}$ : flame temperature.

c $C$ : the percentage of crystallinity. 
$\mathrm{Eu}_{2} \mathrm{O}_{3}$ (all analytical grade) as starting materials, through heating at $1500^{\circ} \mathrm{C}$ for $6 \mathrm{~h}$. The solid-state reaction derived sample was named sample $\mathrm{S}$.

The phases in the prepared samples were examined using a MAC Science MXP3 X-ray powder diffractometer employing $\mathrm{CuK} \alpha 1$ radiation at room temperature. The particle sizes of various samples were calculated from XRD line-width data according to the Debye-Scherrer formula. The morphology and particle size of the prepared samples were analyzed using a Hitachi $\mathrm{H}-7100$ transmission electron microscope (TEM) operated at $75 \mathrm{kV}$. Photoluminescence spectra were recorded using a Hitachi F-4500 fluorescence spectrophotometer employing Hamamatsu 3788 photomultiplier as the light detector, $50 \mathrm{~W} \mathrm{Xe}$ arc discharge lamp as the light source and gratings with a groove density of 1200 lines per $\mathrm{mm}$. The obtained excitation spectra were corrected for the beam intensity variation of the Xe-light source used.

\section{Results and discussion}

\subsection{Preparation of YAG:Eu ${ }^{3+}$ phosphors via the sol-gel pyrolysis process}

Three different values of $\Phi(0.5,1$, and 2.0$)$ were used to prepare YAG:Eu ${ }^{3+}$ phosphors in this study. When the value of $\Phi$ equals unity, maximum energy will be released for the combustion reaction to achieve the target materials. ${ }^{18}$ It should be noted that the samples prepared with $\Phi=2.0$ and $\Phi=0.5$ correspond to fuel-deficient and fuel-rich systems, respectively. The adiabatic flame temperature during the combustion process can be estimated with the following equation:

$T_{\mathrm{f}}=T_{0}+\frac{\Delta H_{\mathrm{r}}-\Delta H_{\mathrm{p}}}{C_{\mathrm{p}}}$

where $T_{\mathrm{f}}$ is the flame temperature, $T_{0}$ is the starting temperature of the reaction; $\Delta H_{\mathrm{r}}$ and $\Delta H_{\mathrm{p}}$, respectively, are the formation enthalpies of the reactants and the products, and $C_{\mathrm{p}}$ is the heat capacity under constant pressure of the products. The flame temperatures for various cases have been calculated and are listed in Table 1. From the XRD patterns, it is found that all the samples prepared in system A and B are well indexable with ICDD file \#33-0040 corresponding to the YAG system (Fig. 2 and 3). Both powders in system $\mathrm{A}$ and $\mathrm{B}$ were calcined at $1000^{\circ} \mathrm{C}$ for $2 \mathrm{~h}$. The percentage of crystallinity $(C)$ for all samples was calculated based on the relative intensity of the (420) diffraction line of the YAG system in various cases with respect to that of the solid-state prepared sample (sample S shown in Fig. 2), and the derived values are summarized in Table 1 . It is obvious that the $C$ value is the maximum for the case of $\Phi=1$, regardless of the type of fuel system used. For different $\Phi$ values, the $C$ values of system A are much higher than those of system B. These results are in agreement with the calculated flame temperature.

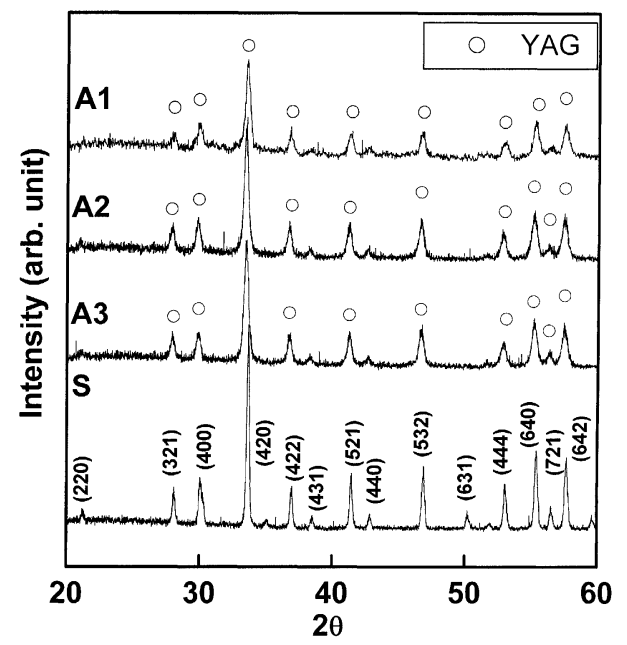

Fig. 2. X-ray diffraction patterns of $\mathrm{YAG}: \mathrm{Eu}^{3+}$ phosphors prepared via sol-gel pyrolysis using PVA and urea combined fuel system (system A). For sample $A_{1}, A_{2}$, and $A_{3}$, the oxidizer to fuel ratio $\Phi$ is equal to 0.5 , 1.0 , and 2.0, respectively. Sample $\mathrm{S}$ is prepared via the solid-state reaction.

\subsection{Microstructures of YAG:Eu ${ }^{3+}$ phosphors prepared via the sol-gel pyrolysis process}

Fig. 4 shows the TEM bright field images of the samples prepared at $\Phi=0.5,1$, and 2 in system A (PVA-urea system) prepared at $1000^{\circ} \mathrm{C}$. It is evident that well dispersed YAG particles (size $\sim 40 \mathrm{~nm}$ ) with a characteristic polyhedral morphology are obtained for the case of $\Phi=1$ in Fig. 4(b). For the sample derived from rich fuel given as depicted in Fig. 4(a), two kinds of particles can be observed, i.e. small particles (size $\sim 35 \mathrm{~nm}$ ) with polyhedral morphology and large particles (size $\sim 150 \mathrm{~nm}$ ) with cuboidal morphology. It is considered that in the case of $\Phi=0.5$, the presence of excess fuel might accelerate the particle growth

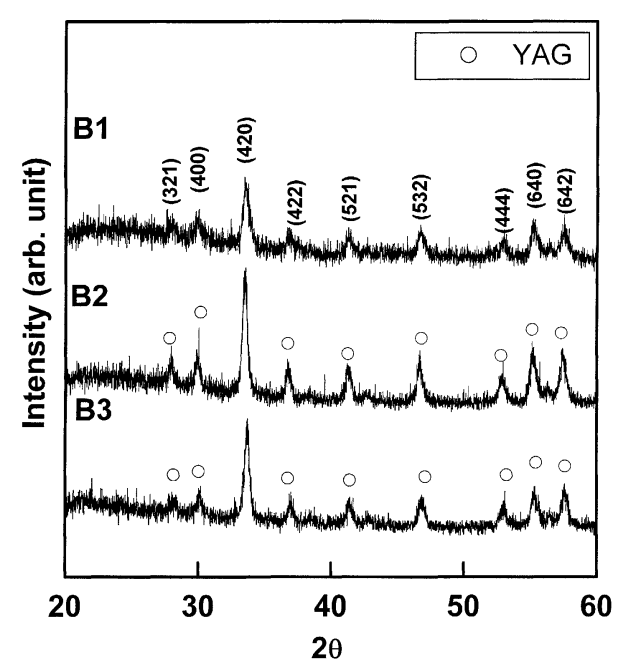

Fig. 3. X-ray diffraction patterns of YAG:Eu ${ }^{3+}$ phosphors prepared via sol-gel pyrolysis using urea only as the fuel (system B). For sample $\mathrm{B}_{1}$, $\mathrm{B}_{2}$, and $\mathrm{B}_{3}$, the oxidizer to fuel ratio $\Phi$ is equal to $0.5,1.0$, and 2.0 , respectively. 

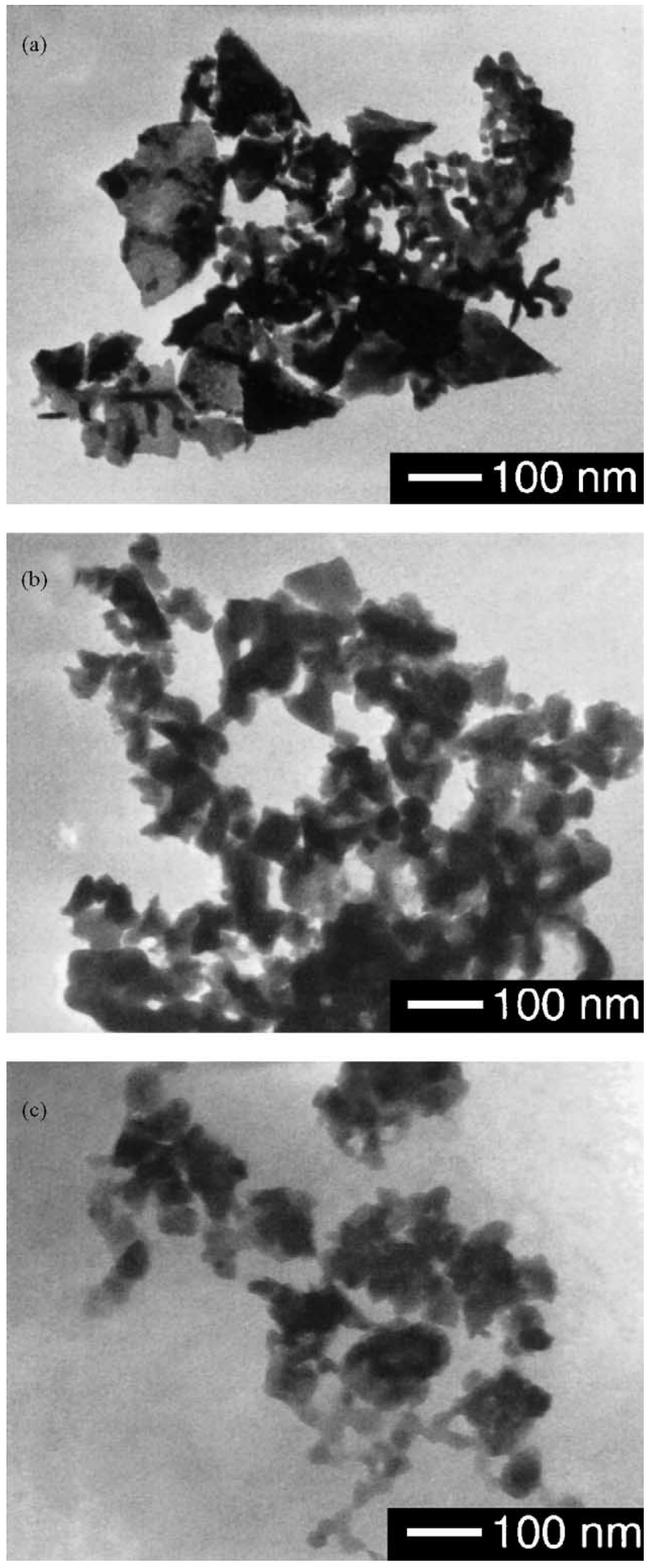

Fig. 4. Transmission electron microscope images of YAG:Eu ${ }^{3+}$ phosphors prepared via sol-gel pyrolysis using PVA and urea combined fuels (system A) with (a) $\Phi=0.5$, (b) $\Phi=1.0$, and (c) $\Phi=2.0$.

process locally and result in particles with different morphologies. For the sample provided with fuel-deficient $(\Phi=$ 2.0) system as shown in Fig.4(c), agglomerates of smaller particles (size $\sim 20 \mathrm{~nm}$ ) having nearly polyhedral morphology were observed. It is not surprising that in the case of

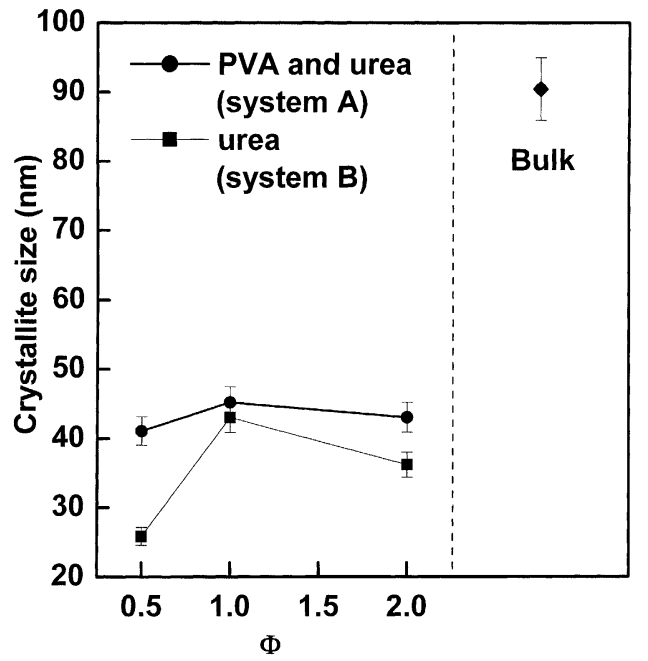

Fig. 5. Crystallite size of YAG:Eu ${ }^{3+}$ phosphors prepared via the sol-gel pyrolysis and solid-state reaction.

fuel-deficient system, the particle growth could not get completed owing to the lack of sustainability of the combustion reaction, therefore, accounting for smaller particles. In addition, the scope of agglomeration might be considerably reduced so that individual crystallites showing single-crystal features were observed.

The values of crystallite size calculated from the (420) XRD peak in conjunction with the Scherrer formula are in agreement with the estimated size derived from the electron microscopy results. The results for the crystallite size as calculated from XRD peak-width data for phosphors of both system A and B prepared at $1000^{\circ} \mathrm{C}$ for $2 \mathrm{~h}$ are given in Fig. 5. This again confirms that nanoparticles with the largest size are obtained only for the case of $\Phi=1$. Also for system $\mathrm{A}$, it is found that the pyrolysis reaction starts at around $800^{\circ} \mathrm{C}$ and produces a highly agglomerated sample with individual crystallites having an average size of $5 \mathrm{~nm}$. Well dispersed nanoparticles are obtained only for samples heated at $1000^{\circ} \mathrm{C}$ and above. The foregoing observations clearly verify that the optimum ratio of oxidizer to fuel for the preparation of well crystallized nanoparticles via the pyrolysis reaction is $\Phi=1$.

For system B that only involved urea as fuel, the corresponding electron microscopy images of samples heated at $100{ }^{\circ} \mathrm{C}$ for $2 \mathrm{~h}$ with different $\Phi$ values are shown in Fig. 6 . This figure clearly suggests a highly agglomerated nature of the YAG particles. In all cases of $\Phi=0.5,1$, and 2, no distinct crystallite features can be observed regardless of the temperature of synthesis $\left(800-1000^{\circ} \mathrm{C}\right)$. These agglomerates might be the result of absence of any organic cages serving as the dispersion agent during the course of pyrolysis reaction. As shown in Table 1, it is found that the percentage of crystallinity $(C)$ in the samples of system $\mathrm{B}$ is approximately $1 / 3$ of that of corresponding samples in system A. Moreover, the theoretical flame temperatures $\left(T_{\mathrm{f}}\right)$ of system B are much lower than those of system A with iden- 

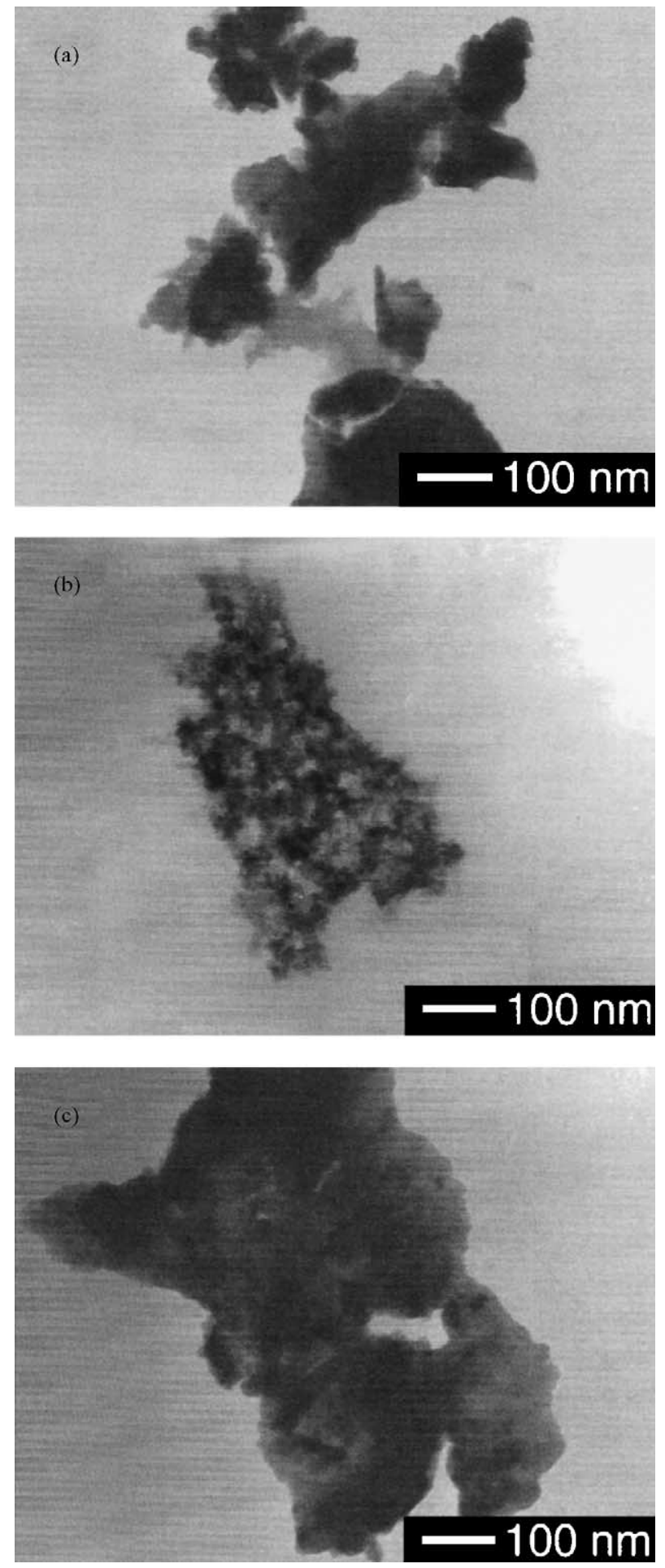

Fig. 6. Transmission electron microscope images of YAG:Eu ${ }^{3+}$ phosphors prepared via sol-gel pyrolyis using urea as the only fuel (system B) with (a) $\Phi=0.5$, (b) $\Phi=1.0$, and (c) $\Phi=2.0$.

tical $\Phi$ values. The decrease in percentage of crystallinity is attributed to the low temperature of sustained pyrolysis reaction. In system A, where the fuel is a mixture of PVA and urea, sufficient heat is generated when the combustion of all the vinyl groups happens. The results in Fig. 4 evi-

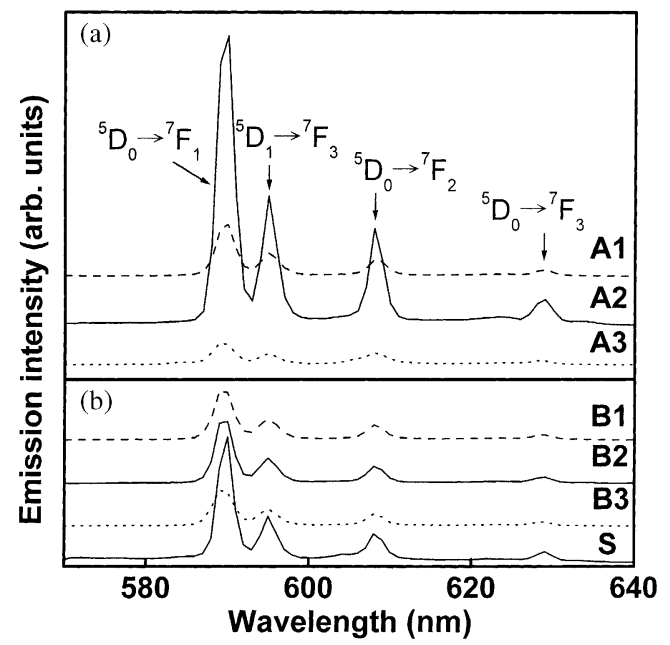

Fig. 7. Photoluminescence emission spectra of YAG:Eu ${ }^{3+}$ phosphors prepared via sol-gel pyrolysis employing (a) PVA and urea, (b) urea only along with YAG:Eu ${ }^{3+}$ samples prepared by the solid-state reaction (under excitation of $220 \mathrm{~nm}$ radiation).

dently demonstrate the necessity to employ an organic polymeric network such as PVA in addition to the fuel for providing organic cages for the preparation of well dispersed nanoparticles. Furthermore, the particle size and morphology of YAG: $\mathrm{Eu}^{3+}$ are found to depend on both the fuels employed and the ratio of oxidizer to fuel.

\subsection{Luminescence transition in $Y A G: E u^{3+}$ phosphors}

Photoluminescence emission spectra of $\mathrm{Eu}^{3+}$ doped YAG prepared by the sol-gel pyrolysis method employing urea and PVA as fuels at different oxidizer to fuel ratios are illustrated in Fig. 7. From this figure, it is found that the red emission around $608 \mathrm{~nm}$ due to ${ }^{5} \mathrm{D}_{0} \rightarrow{ }^{7} \mathrm{~F}_{2}$ transition is weak in this system. This is because it is reduced in the YAG system due to the centrosymmetric surroundings. ${ }^{19}$ On the other hand, the ${ }^{5} \mathrm{D}_{0} \rightarrow{ }^{7} \mathrm{~F}_{1}$ transition involving a magnetic dipole mechanism is structure independent. Therefore, this can serve as an internal standard to assess the strength of the various $\mathrm{f}-\mathrm{f}$ transitions of $\mathrm{Eu}^{3+}$. The intensity ratio of ${ }^{5} \mathrm{D}_{0} \rightarrow$ ${ }^{7} \mathrm{~F}_{2}$ to ${ }^{5} \mathrm{D}_{0} \rightarrow{ }^{7} \mathrm{~F}_{1}$ can be viewed as a clue concerning the nature of the chemical surroundings of the luminescent center and its symmetry. The values of the relative strength of ${ }^{5} \mathrm{D}_{0} \rightarrow{ }^{7} \mathrm{~F}_{2}$ to ${ }^{5} \mathrm{D}_{0} \rightarrow{ }^{7} \mathrm{~F}_{1}$ for sample $\mathrm{A}_{2}$ and $\mathrm{S}$ are 0.5 and 0.24 , respectively. It indicates that in the case of YAG:Eu ${ }^{3+}$ nanoparticles $\left(\mathrm{A}_{2}\right)$, there is a doubling in the intensity of the ${ }^{5} \mathrm{D}_{0} \rightarrow{ }^{7} \mathrm{~F}_{2}$ transition. This suggests that slightly modified chemical surroundings can enhance the transition strength of the hypersensitive transition.

Based on the emission spectra given in Fig. 7, it is obvious that sample $A_{2}$ shows the maximum luminescence intensity, which is three times higher than that of the bulk sample $\mathrm{S}$ (with a size of $0.9 \mu \mathrm{m}$ ) prepared by solid-state reaction. The luminescence enhancement in the case of nanophosphors can be explained from the excitation spectra monitoring the 


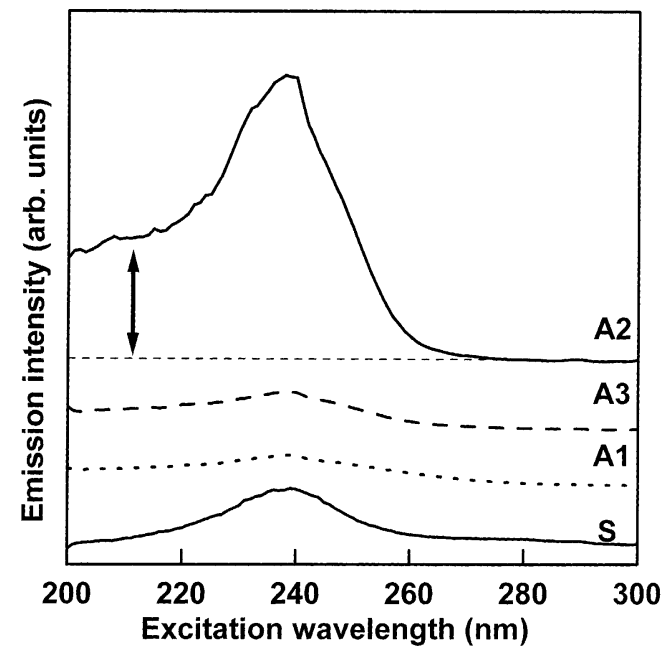

Fig. 8. Photoluminescence excitation spectra of $\mathrm{YAG}: \mathrm{Eu}^{3+}$ phosphors prepared using sol-gel pyrolysis and the bulk sample, corresponding to emission at $608 \mathrm{~nm}$ due to ${ }^{5} \mathrm{D}_{0} \rightarrow{ }^{7} \mathrm{~F}_{2}$ electric dipole transition. The solid arrow shows the presence of the sideband around band edge of the YAG system in particular for the nanoparticles prepared using PVA and urea as fuels $\left(\mathrm{A}_{2}\right)$.

hypersensitive ${ }^{5} \mathrm{D}_{0} \rightarrow{ }^{7} \mathrm{~F}_{2}$ emission in Fig. 8. The emission wavelength was fixed at $608 \mathrm{~nm}$. All these samples demonstrate strong excitation peaks at $240 \mathrm{~nm}$, which conforms to the value of the charge transfer band in the YAG:Eu ${ }^{3+}$ system. ${ }^{20}$ However, it can also be noted that the nanocrystalline sample $\left(A_{2}\right)$ exhibits an extension of the excitation spectrum in the short wavelength region (at around $220 \mathrm{~nm}$ ) while the bulk counterpart (sample $S$ ) does not show such an excitation band. The presence of an extension of the excitation band corresponding to the charge transfer band can be explained by considering multiple surface states because of the large surface area in the nanocrystalline sample. These surface states in the nanocrystals arise from unsaturated chemical bonds, different chemical coordination, and broken lattice periodicity. Owing to the large surface to volume ratio, these surface states play a prominent role in nanocrystals. Under photoexcitation near $220 \mathrm{~nm}$, the tendency to undergo charge transfer will be more pronounced. Therefore, stronger charge transfer transitions providing the energy to the excited ${ }^{5} \mathrm{D}$ levels can lead to luminescence enhancement in well dispersed nanocrystals. On the other hand, the case of agglomerates comprising nanoparticles such as sample $\mathrm{B}_{2}$ appears to be quite different in that the role of surface states seems to be less pronounced. In the case of agglomerates, the particle-to-particle contact may modify the unsaturated bonds on the surface of the crystallites and provide alternative non-radiative relaxation path in the same manner as the situation in the bulk system. Fig. 9 illustrates the energy level diagram of the well dispersed YAG:Eu ${ }^{3+}$ nanoparticles. For the well dispersed nanoparticles, the existence of enormous surface states (SS) results in additional charge transfer transition (CTS). This additional transition (CTS) besides the charge transfer band (CTB) will provide energy to the ${ }^{5} \mathrm{D}_{\mathrm{J}}$

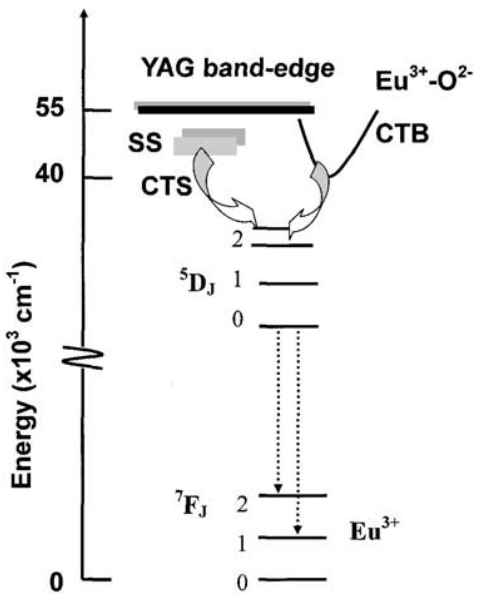

Fig. 9. Schematic diagram of the energy levels in the well dispersed YAG: $\mathrm{Eu}^{3+}$ nanoparticles. The gray blocks denote the positions of surface states (SS). CTB indicates the $\mathrm{Eu}^{3+}-\mathrm{O}^{2-}$ charge transfer band in the general YAG:Eu ${ }^{3+}$ system. CTS represents the charge transfer due to the existence of enormous surface states.

states of $\mathrm{Eu}^{3+}$, and the absorbed energy in ${ }^{5} \mathrm{D}_{\mathrm{J}}$ states will transfer to ${ }^{7} \mathrm{~F}_{\mathrm{J}}$ states. Hence, the charge transfer to $\mathrm{Eu}^{3+}$ will become more probable, leading to the enhancement of luminescence emission in the YAG: $\mathrm{Eu}^{3+}$ nanoparticles.

\section{Conclusions}

Sol-gel polymer pyrolysis method employing urea and PVA combined fuel system appears to be a feasible way for the synthesis of YAG:Eu ${ }^{3+}$ nanophosphors at low temperatures. Through this method, well dispersed nanoparticles having an average size of $40 \mathrm{~nm}$ can be obtained. Well dispersed nanoparticles are obtained when the oxidizer to fuel ratio $(\Phi)$ is maintained at an optimum value of 1 . On the other hand, when urea is used as the only effective fuel (i.e. in the absence of polymeric network in the process), seriously agglomerated YAG particles will be obtained. Results based on $\mathrm{Eu}^{3+}$ luminescence serving as a local probe confirm these microstructural changes in these samples. Furthermore, $\mathrm{Eu}^{3+}$ luminescence in this nanoceramic system shows a size-dependent luminescence enhancement that can be attributed to pronounced surface states having charge transfer origin. The luminescence enhancement observed in the nanophosphors is of practical importance for this system to be applied to field emission devices.

\section{References}

1. Wang, H. and Gao, L., Preparation and microstructure of polycrystalline $\mathrm{Al}_{2} \mathrm{O}_{3}-\mathrm{YAG}$ composites. Ceram. Int. 2001, 27, 721-723.

2. Rhodes, W. H., Controlled transient solid second-phase sintering of yttria. J. Am. Ceram. Soc. 1981, 64, 13-19.

3. Greskovich, C. and Chernoch, J. P., Polycrystalline ceramic lasers. $J$. Appl. Phys. 1973, 44, 4599-4606. 
4. Schlotter, P., Schmidt, R. and Scneider, J., Luminescence conversion of blue light emitting diodes. Appl. Phys. 1997, 64, 417-418.

5. Ravichandran, D., Roy, R., Chakhovskoi, A. G., Hunt, C. E., White, W. B. and Erdei, S., Fabrication of $\mathrm{Y}_{3} \mathrm{Al}_{5} \mathrm{O}_{12}$ :Eu thin films and powders for field emission display applications. J. Luminescence 1997, 71, 291-297.

6. Zhou, Y. H., Preparation of $\mathrm{Y}_{3} \mathrm{Al}_{5} \mathrm{O}_{12}: \mathrm{Eu}$ phosphors prepared by citric-gel method and their luminescent properties. Opt. Mater. 2002, 20, 13-20.

7. Lu, C.-H. and Jagannathan, R., Cerium-ion-doped yttrium aluminum garnet nanophosphors prepared through sol-gel pyrolysis for luminescent lighting. Appl. Phys. Lett. 2002, 80, 3608-3610.

8. Lu, C.-H., Hong, H. C. and Jagannathan, R., Sol-gel synthesis and photoluminescent properties of cerium-ion doped yttrium aluminum garnet powders. J. Mater. Chem. 2002, 12, 2525-2530.

9. Kinsman, K. M. and McKittrick, J., Phase development and luminescence in chromium-doped yttrium aluminum garnet (YAG:Cr) phosphors. J. Am. Ceram. Soc. 1994, 77, 2866-2872.

10. Ohno, K. and Abe, T., Effect of $\mathrm{BaF}_{2}$ on the synthesis of the single-phase cubic $\mathrm{Y}_{3} \mathrm{Al}_{5} \mathrm{O}_{12}: \mathrm{Tb}$. J. Electrochem. Soc. 1986, 133, 638-643.

11. Matsushita, N., Tsuchiya, N. and Nakatsuka, K., Precipitation and calcinations process for yttrium aluminum garnet precursors synthesized by the urea method. J. Am. Ceram. Soc. 1999, 81, 1977-1984.

12. Wang, H., Gao, L. and Niihara, K., Synthesis of nanoscaled yttrium aluminum garnet powder by the co-precipitation method. Mater. Sci. Eng. 2000, 288, 1-4.
13. Nyman, M., Caruso, J. and Hampden-Smith, M., Comparsion of solid-state and spray-pyrolysis synthesis of yttrium aluminate powders. J. Am. Ceram. Soc. 1997, 80, 1231-1238.

14. Kang, Y. C., Lenggoro, I. W., Park, S. B. and Okuyama, K., Photoluminescence characteristics of YAG:Tb phosphor particles with spherical morpjology and non-aggregation. J. Phys. Chem. Solids 1999, 60, $1855-1858$.

15. Shea, L. E., McKittrick, J. and Lopez, O. A., Synthesis of red-emitting, small particle size luminescent oxides using an optimized combustion process. J. Am. Ceram. Soc. 1996, 79, 3257-3265.

16. McKittrick, J., Shea, L. E., Bacalski, C. F. and Bosze, E. J., The influence of processing parameters on luminescent oxides produced by combustion synthesis. Dislays 1999, 19, 169-172.

17. Dhanaraj, J., Jagannathan, R., Kutty, T. R. N. and Lu, C.-H., Photoluminescence characteristics of $\mathrm{Y}_{2} \mathrm{O}_{3}: \mathrm{Eu}^{3+}$ nanophosphors prepared using sol-gel thermolysis. J. Phys. Chem. B 2001, 105, 1109811105 .

18. Robbins, D. J., Relationship between concentration and efficiency in rare earth activated phosphors. J. Electrochem. Soc. 1979, 126, 15501563.

19. Ruan, S. K., Zhou, J. G., Zhong, A. M., Duan, J. F., Yang, X. B. and $\mathrm{Su}$, M. Z., Synthesis of $\mathrm{Y}_{3} \mathrm{Al}_{5} \mathrm{O}_{12}: \mathrm{Eu}^{3+}$ phosphor by sol-gel method and its luminescence behavior. J. Alloy Compd. 1998, 72-75, 7275.

20. Shi, S. and Wang, J., Combustion synthesis of $\mathrm{Eu}^{3+}$ activated $\mathrm{Y}_{3} \mathrm{Al}_{5} \mathrm{O}_{12}$ phosphor nanoparticles. J. Alloy Compd. 2001, 327, 8286. 